\title{
Desain Workstation Dental Simulator untuk Laboratorium Fakultas Kedokteran Gigi
}

\author{
Taufik Hidayat, Andhika Estiyono, Arie Kurniawan, dan Ari Dwi Krisbianto \\ Departemen Desain Produk, Fakultas Desain Kreatif dan Bisnis Digital \\ Institut Teknologi Sepuluh Nopember, Surabaya, Indonesia \\ e-mail: zota@prodes.its.ac.id
}

\begin{abstract}
Abstrak-Dental simulator merupakan salah satu media praktikum pada fakultas kedokteran gigi. Terdapat banyak sekolah kedokteran gigi di Indonesia yang membutuhkan peralatan dental simulator dalam media pembelajarannya. Aspek yang dibutuhkan dalam perancangan dental simulator meliputi aspek ergonomi, aspek efisiensi, aspek kualitas dan aspek ekonomi. Dimensi produk sangat dipengaruhi oleh aspek ergonomi, ditentukan pula oleh ruang dan studi yang diperoleh dari eksisting. Eksisting merupakan produk yang selama ini dipakai oleh sekolah kedokteran gigi dan produk import yang akan dilakukan reverse engineering. Penelitian dilakukan dengan cara melakukan perubahan meja eksisting yang digunakan oleh sekolah dengan penambahan komponen import. Selanjutnya akan dilakukan pengembangan prototipe yang lebih baik sesuai kebutuhan. Manfaat yang diharapkan dalam penelitian ini adalah desain baru yang mampu menjadi pengganti workstation yang diimport secara utuh sehingga lebih ekonomis, pemberdayaan UKM, peningkatan teknologi dan komponen dalam negeri serta mampu menghasilkan sebuah workstation yang lebih sesuai sekolah kedokteran gigi di Indonesia.
\end{abstract}

Kata kunci: workstation, praktikum, dental simulator, ergonomi, reverse engineering

\begin{abstract}
Dental simulator is one of the practicum media in the faculty of dentistry. There are many dental schools in Indonesia which require dental simulator equipment in their learning process. Aspects needed in the design of dental simulators include ergonomics, efficiency, quality, and economic. The dimensions of the product are strongly influenced by the ergonomics aspects, also determined by the space and studies obtained from the existing. Existing includes products that have been used by dental schools and imported products that have been reverse engineering. The study was conducted by changing the existing table with the addition of imported components. Next, it will be done better prototype development and ready to be applied. The expected benefits in this research are, a new design that is able to replace workstations that are imported as a whole so that it is more economical, empowering SMEs, improving technology and domestic components and being able to produce a workstation that is more suitable and meets the needs of a dental school in Indonesia.
\end{abstract}

Keywords: workstation, practice, dental simulator, ergonomics, reverse engineering

\section{PENDAHULUAN}

Dental simulator merupakan media pembelajaran yang menggunakan simulasi manekin untuk melatih para siswa kedokteran gigi dalam hal ketrampilan klinik [1]. Tujuan utama dari pembelajaran simulasi ini adalah untuk melatih siswa mencapai kompetensi tinggi sebelum memulai praktik klinis [2].

Studi aktivitas di lapangan dalam menjalankan perawatan gigi dalam mulut memerlukan sebuah posisi yang bisa meng-handle penuh dengan gerakan dan kekuatan yang terkontrol [3]. Diperlukan sebuah postur yang benar agar kapasitas kerja dan produktivitas meningkat. Selain itu lingkungan kerja harus nyaman untuk melakukan perawatan gigi yang berkualitas [4]. Hal ini sangat dipengaruhi oleh luasan, ruang dan konfigurasi penataan unit.

Kelelahan paling besar yang dialami oleh dokter gigi adalah pada punggung bagian bawah (tulang belakang bawah) yang disebabkan oleh kesalahan posisi selama merawat gigi pasien [5]. Selain itu selama proses perawatan, sebaiknya memiliki kemudahan bergerak bebas untuk mengakses peralatan dan material yang dibutuhkan [6].

Workstation yang layak harus terpenuhi: (1) Tinggi kursi dokter gigi atau pasien yang sesuai; (2) Lumbar, toraks, atau penyangga lengan di kursi dokter gigi; (3) Posisi tabel instrumen; (4) Pencahayaan yang memadai; (5) Tepi permukaan kerja yang nyaman; (6) Ventilasi yang tepat; dan (7) Temperatur ruangan yang sesuai [7].

Untuk mengejar efisiensi dan menghindari kelelahan, siswa melakukan aktivitas dengan posisi duduk. Namun selama praktik, kebutuhan untuk melihat langsung dengan visual yang lebih baik menyebabkan siswa harus berubah posisi sehingga terkadang kehilangan kontrol atas postur kerja yang tepat [8].

Untuk bahan yang sesuai dengan perangkat, mengingat produk yang akan dibuat adalah peralatan medis maka terdapat kriteria-kriteria dalam pemilihannya, antara lain: (1) Ketersediaan material; (2) Fleksibilitas bahan terhadap target desain; (3) Harga material; (4) Kesesuaian antara sifat material dan spesifikasi yang diperlukan dari perangkat yang dirancang; (5) Pemilihan bahan terpercaya/bersertifikat untuk aplikasi medis; (6) Biokompatibilitas perangkat rancangan akhir beserta komponennya; (7) Sesuai dengan teknik sterilisasi yang digunakan; (8) Kegunaan perangkat; (9) Pemilihan material yang menjamin manufaktur yang efisien; dan (10) Keberlanjutan perangkat medis [9]. Kesesuaian komponen dengan material properties yang sesuai kebutuhan medis akan dipertimbangkan berdasarkan sifat, tipe, competing material, lingkungan dan catatan teknis [10].

Diharapkan hasil dari perancangan akan memberikan alternatif workstation dental simulator yang lebih ekonomis, 
tetap berfungsi sesuai standar kebutuhan medis pendidikan kedokteran berdasarkan aktivitas dan luasan tempat belajar (space) dan dapat memberdayakan UKM.

\section{METODE PENELITIAN}

Diawali dengan studi hasil penelitian sebelumnya oleh inovator kemudian dilanjutkan dengan studi perbandingan produk kompetitor. Setelah mengetahui dimensi, letak dan komponennya, dilaksanakan proses reverse engineering dan pengembangan prototipe yang sesuai dengan kebutuhan desain. Studi ergonomi dilakukan dengan observasi dan wawancara lapangan secara kualitatif untuk mengetahui titik kritis dan posisi yang nyaman. Hasil riset awal didapatkan purwarupa digital dengan metode Integrated Digital Design. Di akhir, dilakukan pengujian produk untuk mengetahui kesesuaian dimensi dan aktivitas (Gambar 1).

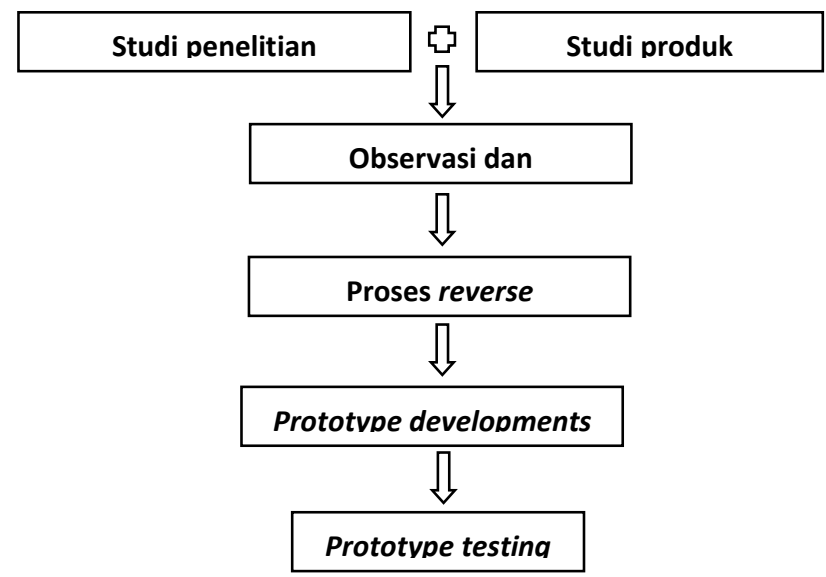

Gambar 1. Alur penelitian desain workstation dental simulator.

\section{HASIL DAN PEMBAHASAN}

\section{Studi eksisting dan lapangan}

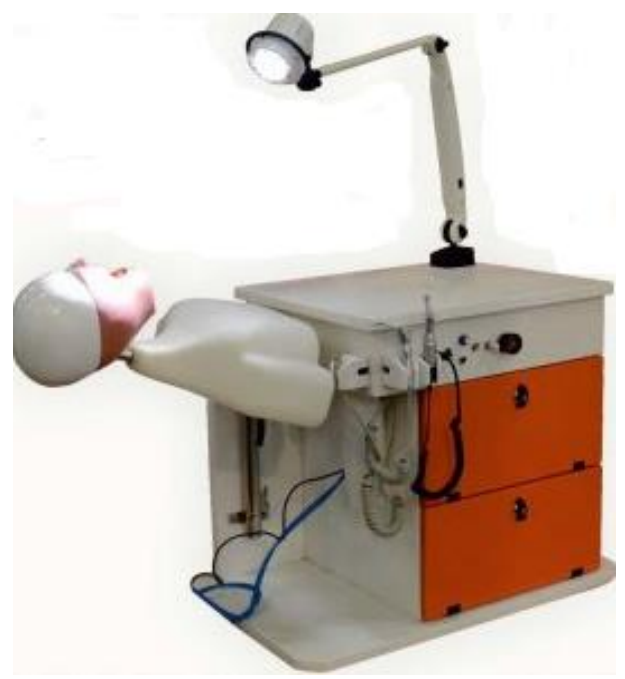

Gambar 2. Eksisting Workstation dental simulator impor yang ada di pasar Indonesia.

Sumber: https://www.navadha.com/simdec.html
Vol. 19, No.2, Oktober 2020, pISSN 1411-3023, eISSN 2580-0264

Sebuah workstation dental simulator biasanya berupa sebuah meja dengan manekin kepala/mulut yang diletakkan seperti posisi pasien pada saat praktik sebenarnya. Dilengkapi dengan beberapa peralatan operasi gigi dengan lampu pada lengan artikulasi (Gambar 2).

Beberapa laboratorium kedokteran gigi menyiasati fungsi workstation tersebut dengan memodifikasi meja biasa sesuai dengan kebutuhan dan ditambahkan komponen dan peralatan pendukung praktikum. Namun eksisting yang ada masih perlu banyak perbaikan (Gambar 3).
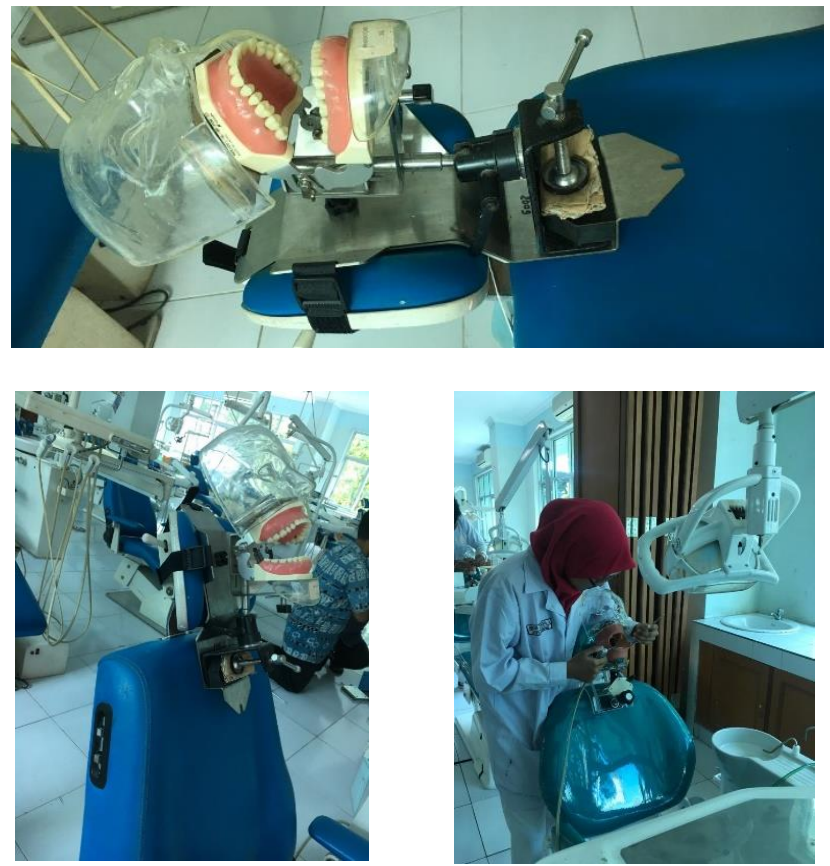

Gambar 3. Workstation eksisting dental simulator hasil modifikasi. Sumber: Dokumen laboratorium protomodel Desain Produk ITS.

Sesuai kebutuhan pembelajaran, peralatan yang harus ada pada workstation meliputi:

1. Manekin kepala (phantom head) berupa sebuah model kepala manusia dengan fitur montase gigi tiruan yang bisa diatur posisinya.

2. Peralatan perawatan gigi bermotor meliputi mesin gerinda mini, penyembur air, penghisap air, lampu pengeras semen dan peniup angin.

3. Peralatan tidak bermotor berupa peralatan tangan seperti sonde, pisau bedah, suntikan, bor lubang saraf gigi dan peralatan kecil lain. Pengaturan peralatan bermotor menggunakan pedal yang diletakkan pada lantai.

4. Bahan-bahan untuk perawatan gigi berupa semen gigi, kapas, obat-obatan, kawat gigi dan bahan lainnya

5. Sistem pencahayaan terpusat pada lengan artikulator dan bisa diatur posisinya.

6. Kontainer limbah operasi berupa wadah untuk menampung cairan sisa operasi.

Studi awal tentang dimensi dan ergonomi terdiri atas studi ruang (kelas/laboratorium yang digunakan), aktivitas dan studi eksisting. Optimalisasi kapasitas terhadap ruang dengan didasarkan pada dimensi ruang kelas dengan dimensi workstation (Gambar 4), kemudian dicari dimensi yang paling efisien agar cukup maksimal jumlah peserta namun masih memperhatikan kenyamanan jarak/space dan pengawasan (Gambar 5). 


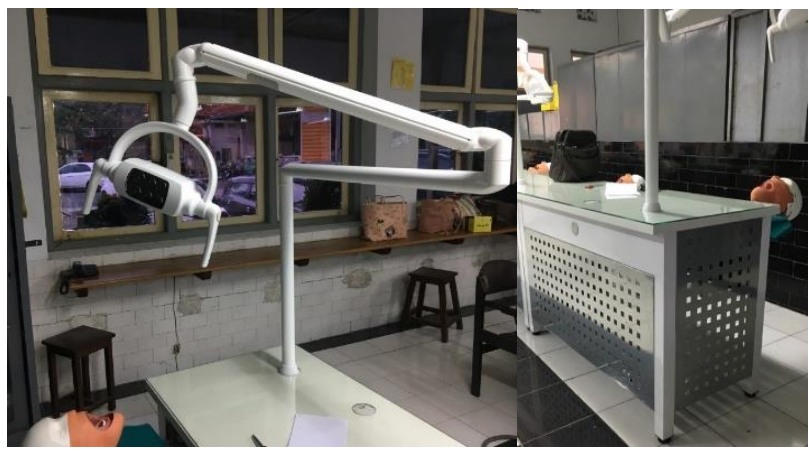

Gambar 4. Studi awal tentang eksisting modifikasi workstation.

Untuk menentukan dimensi meja dental simulator dibutuhkan riset terkait konfigurasi dan penempatan meja pada ruangan. Studi Konfigurasi workstation yang efisien 1 meja untuk 2 siswa sesuai dengan aktivitas utama yaitu praktikum gigi pada manekin dan penulisan laporan praktikum, seperti dapat dilihat pada Gambar 6.

Gambar 7 menunjukkan studi alternatif konfigurasi 10 siswa dengan 1 dosen pengawas. Membutuhkan ruang sebesar 3,2 $\mathrm{m} \times 3,7 \mathrm{~m}$.

Studi pengelolaan ruang studi kasus ruang praktikum. Untuk memberi gambaran aplikasi pada ruang praktikum dengan konfigurasi 8 siswa dengan 1 dosen pengawas. Konfigurasi ini dipilih karena lebih sesuai dengan kebutuhan, kenyamanan dan kondisi ruangan yang ada, seperti dapat dilihat pada Gambar 8.

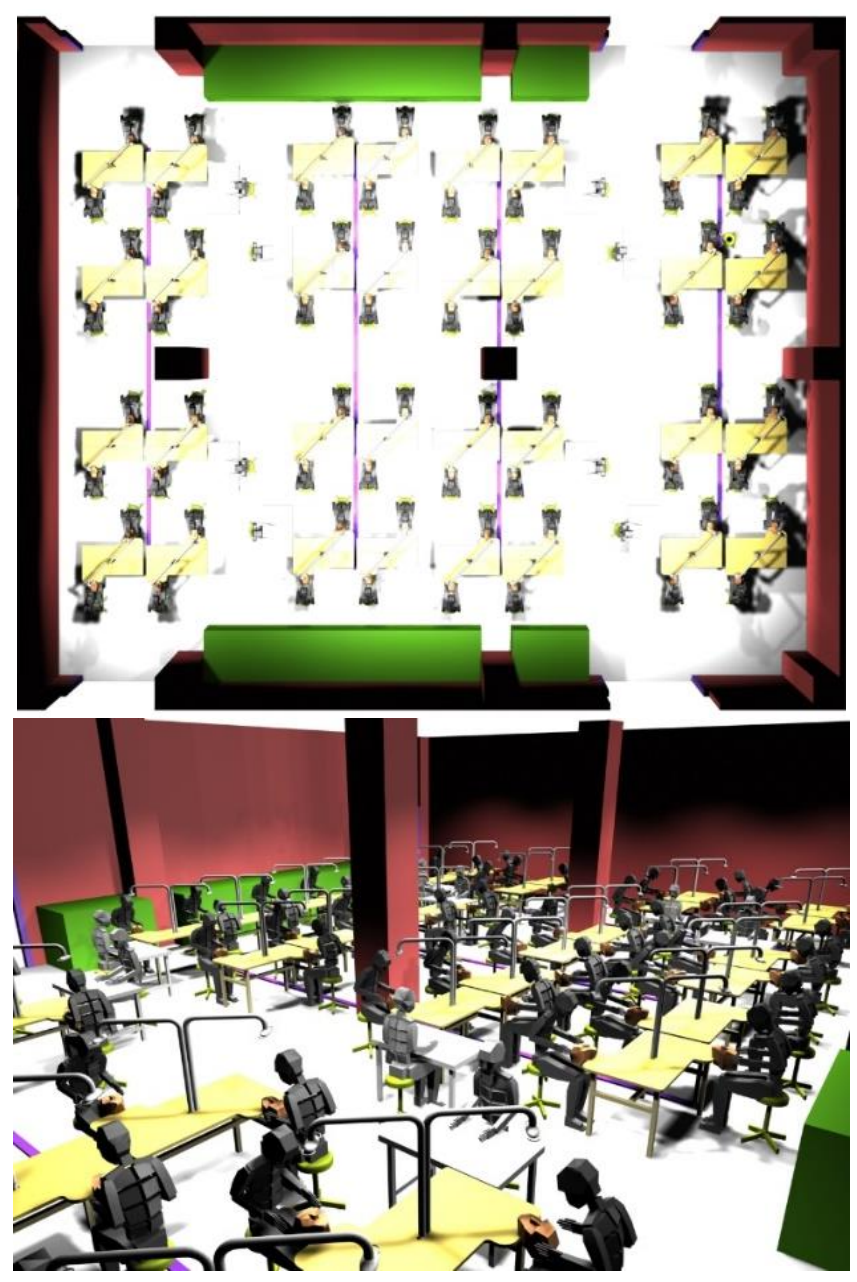

Gambar 5. Studi awal tentang tata letak workstation.

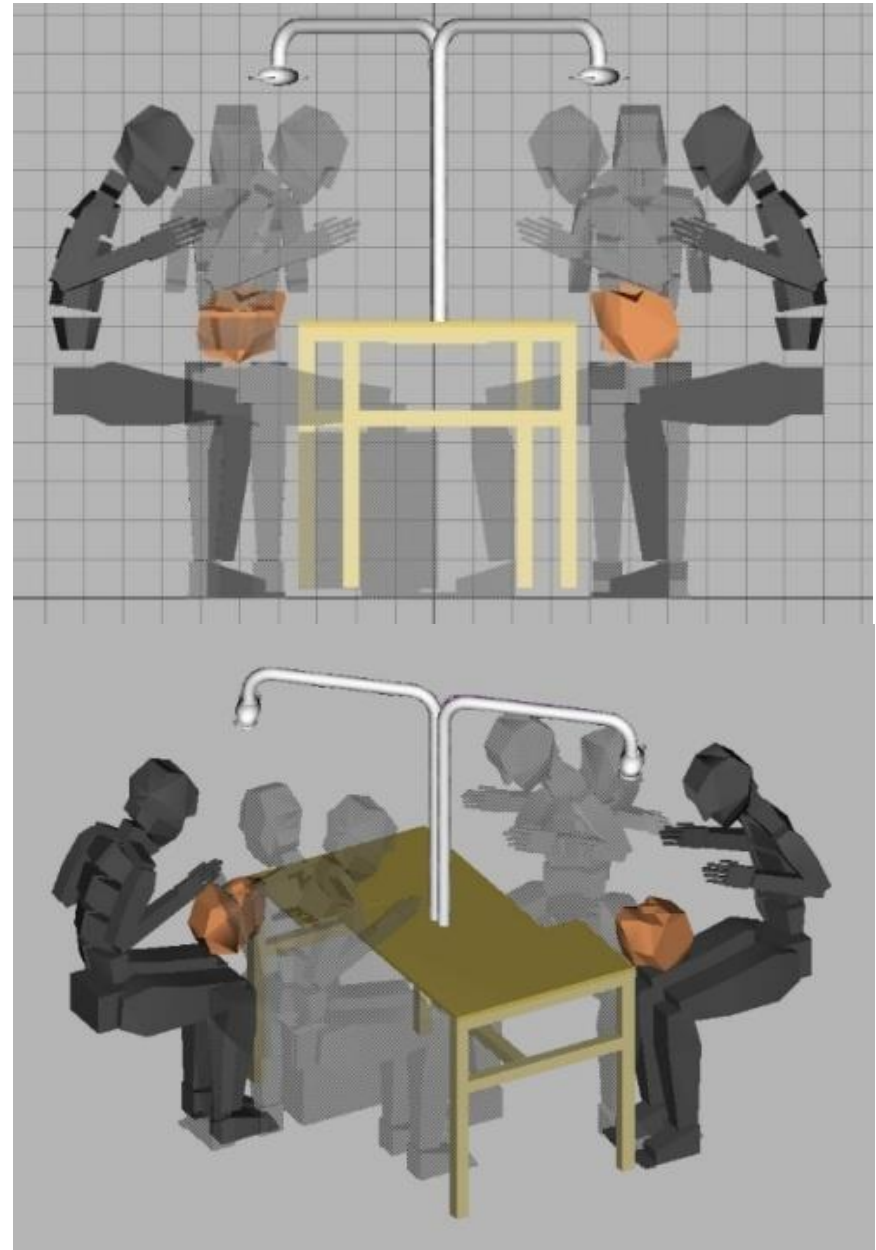

Gambar 6. Konfigurasi workstation untuk aktivitas utama praktikum gigi dan penulisan laporan.

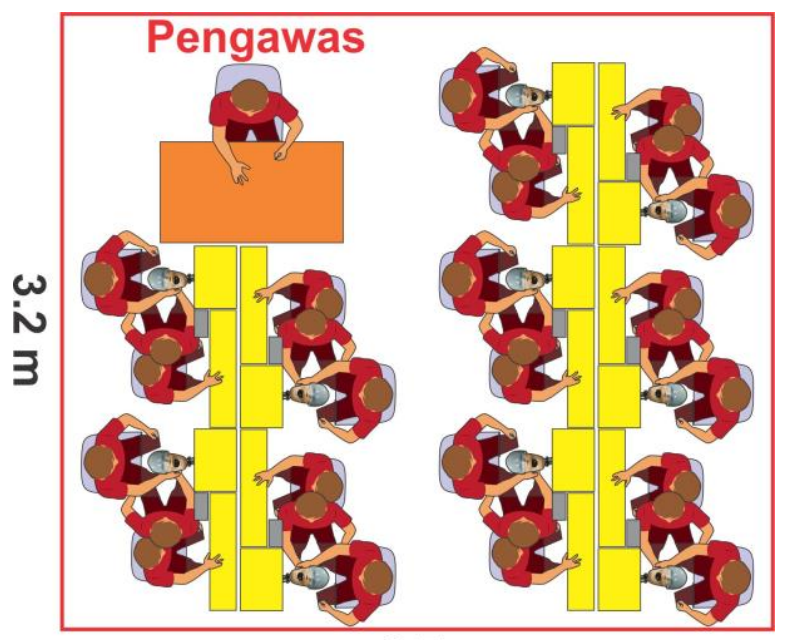

$3.7 \mathrm{~m}$

Gambar 7. Studi ruang konfigurasi meja praktikum siswa dan meja dosen.

\section{Studi perbandingan terhadap produk kompetitor}

Model produk pertama, workstation sudah terdapat dummy tubuh berupa bahu sampai leher dengan penahan bodi yang dapat diputar sesuai dengan arah dan sudut kenyamanan posisi pada saat melakukan praktik. Workstation dilengkapi dengan kaki beroda agar dapat digeser berpindah tempat. Mempunyai dimensi lebar yang cukup kecil agar praktikan mampu mendekat dengan membuka tungkai kaki (Gambar 9). 

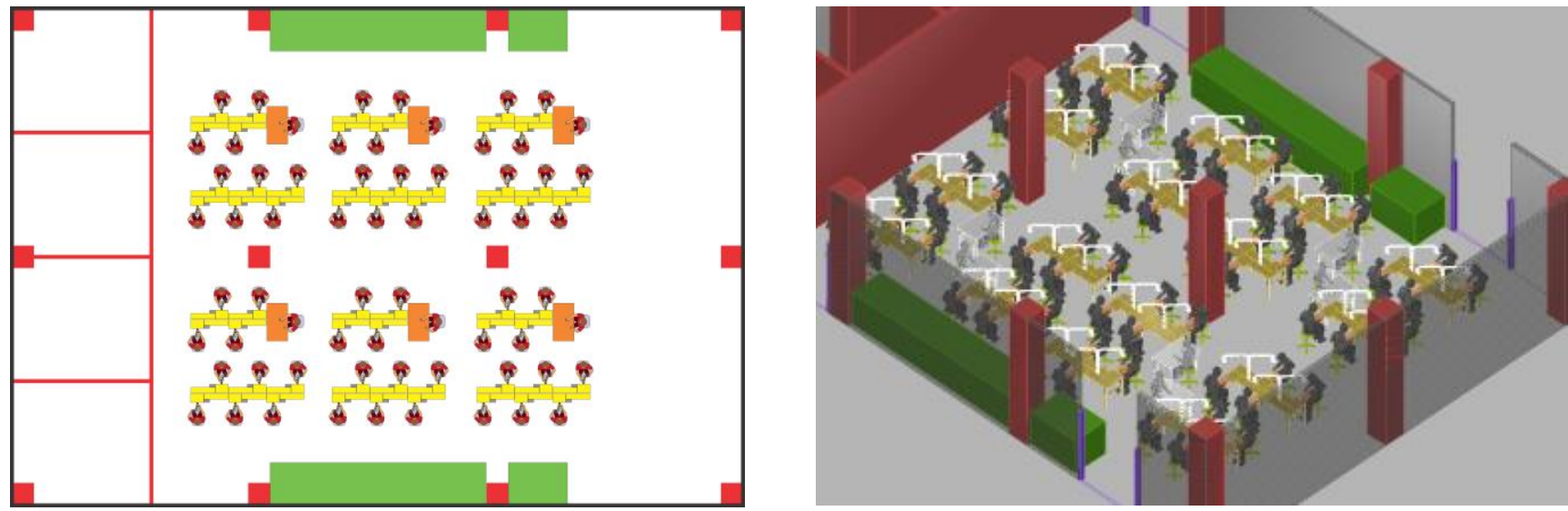

Gambar 8. Implementasi konfigurasi

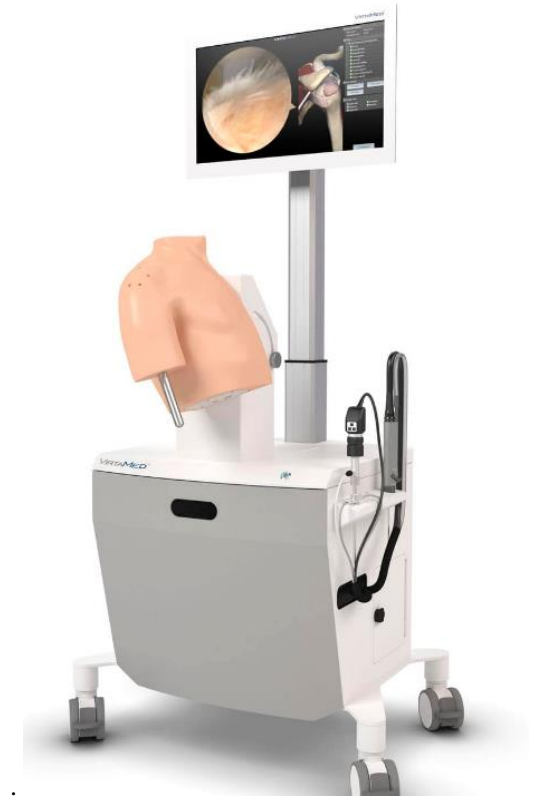

Gambar 9. Virtamed dental workstation.

Sumber: http://www.medicalexpo.com/prod/virtamed/

Model produk kedua, terdapat perbedaan posisi postur letak manekin yang berada agak ke bawah. Keuntungan dari letak seperti dapat dilihat pada Gambar 10 adalah praktikan mampu melakukan praktik dengan langsung membawahi dengan arah dan sudut yang bebas.

Persamaan dan perbedaan kedua produk dapat diuraikan sebagai berikut.

Persamaannya :

1. Mempunyai bentuk dominan meja dan/atau laci

2. Terdapat pergerakan part untuk kemudahan akses.

Perbedaannya :

Tidak semuanya .mampu digerakkan minimal ada satu. Dalam hal ini yang digerakkan mejanya dan manekin berada terpaku pada penyangga di atas meja. Sedangkan model berikutnya yang digerakkan adalah penyangga manekinnya itu sendiri.

\section{Aspek ergonomi desain meja Dentistry}

Hal yang menjadi perhatian berkaitan dengan ergonomi peralatan praktikan kedokteran gigi adalah postur tubuh, posisi tangan, posisi lengan dan posisi tubuh praktikan dengan kepala pasien. Posisi yang disarankan:
1. Leher, bahu dan otot punggung tidak boleh dalam ketegangan

2. punggung berada dalam posisi tubuh yang tidak terlalu condong ke depan sehingga mengalami tekanan

3. posisi peralatan harus dalam keadaan seimbang

4. komponen yang berupa peralatan harus dapat mengakomodasi penggunaan dari arah kanan dan kiri

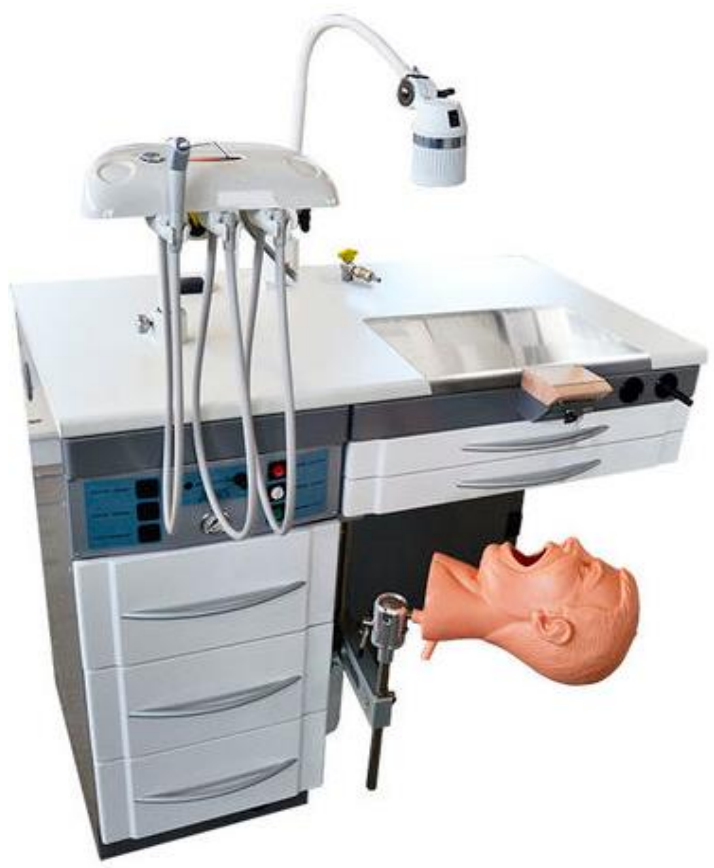

Gambar 10. Aries dental workstation

Sumber: http://www.medicalexpo.com/prod/aries-medical-srl/

\section{Penanggulangan gangguan muskuloskeletal pada meja Dokter Gigi}

Gangguan muskuloskeletal (gejala kekakuan otot bahu, leher, punggung, kesemutan pada telapak dan jari-jari tangan, nyeri hebat pada punggung bagian bawah sangat sering ditemukan sehubungan dengan jenis pekerjaan, termasuk pada dokter gigi. Posisi kerja yang menetap dan kaku saat merawat pasien, peralatan yang digunakan tidak ergonomis merupakan faktor risiko (high risk) dokter gigi mengalami gangguan muskuloskeletal. Salah satu upaya pencegahan yang dapat dilakukan adalah: menggunakan peralatan yang ergonomis. 

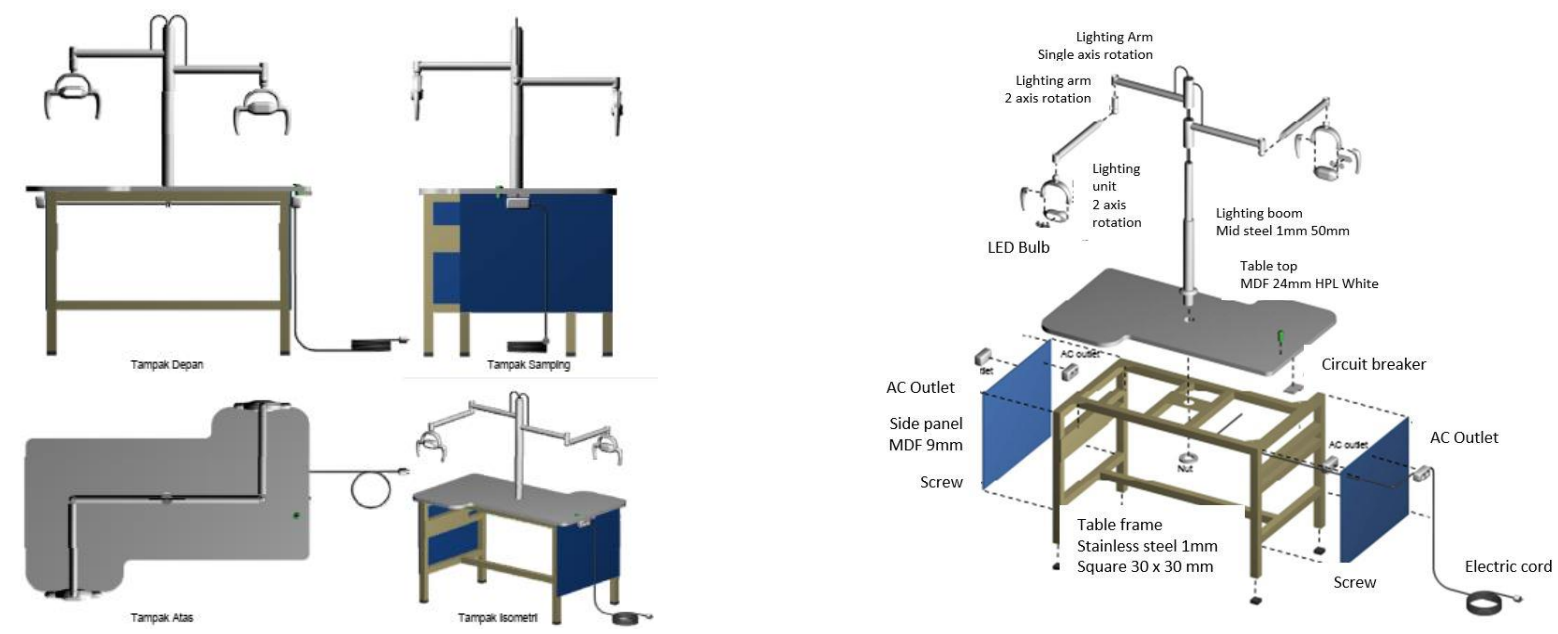

Gambar 11. Visual implementasi desain.

Pada penelitian sebelumnya, beberapa cara pencegahan gangguan Muskuloskeletal dengan pendekatan ergonomi antara lain:

1. Gunakan kursi dental dengan sistem ergonomi berupa kursi dental yang dapat disesuaikan mengikuti posisi postur pasien dengan tepat.

2. Posisi dokter gigi dengan pasien lebih dekat. Hal ini ditujukan untuk menghindari postur yang membungkuk yang dapat menyebabkan rasa sakit pada punggung dan leher.

3. Hindari kecenderungan dokter gigi untuk menyesuaikan posisi terhadap pasien, namun usahakan pasien didudukkan sesuai dengan posisi yang benar bagi dokter gigi.

4. Hindari mengangkat siku atau lengan terlalu tinggi untuk mencegah otot terlalu tegang.

5. Siapkan waktu untuk memposisikan pasien pada posisi horisontal (terlentang) dengan sudut yang benar, pada saat melakukan perawatan untuk gigi rahang atas, sedangkan posisi pasien setengah horisontal untuk perawatan gigi rahang bawah.

6. Gunakan bantal di bawah leher pasien untuk mempertahankan posisi kepala yang benar selama melakukan perawatan gigi pada rahang atas.

7. Gunakan dental-loupe untuk membantu penglihatan agar tidak terjadi kelelahan pada mata.

Pada ruang kerja dokter gigi terdapat dua jenis furnitur operasional yang perlu diperhatikan kenyamanannya, yaitu operating stool (kursi operasi) dan operator table (meja dari kursi dental). Operating Stool: adalah kursi yang digunakan dokter gigi ketika memeriksa pasien. Bentuk tempat duduk dirancang untuk membantu tubuh dokter dalam posisi yang benar dengan spinal yang tegak dan dekat dengan kursi gigi. Bentuk sandaran yang mendukung punggung agar otot punggung bagian bawah tetap tegak dan lengkungannya dipertahankan. Sandaran lengan dirancang untuk mengurangi tekanan dan kelelahan pada otot-otot punggung bagian atas, leher dan bahu dengan membentuk sudut tegak lurus terhadap siku lengan dokter gigi.

Operator Table merupakan meja dari kursi dental yang memungkinkan pergerakan posisi vertikal dan horisontal, sehingga dapat disesuaikan dengan posisi operator berada. Kursi dental dengan sandaran kepala dan belakang yang lebar serta tebal akan menyulitkan operator bekerja lebih dekat dengan pasien, sehingga cenderung membungkuk ke arah pasien. Kursi dental yang ergonomis adalah dengan sandaran kepala yang sempit dan tipis. Bentuk demikian memungkinkan operator meletakkan tangannya dengan mudah di bawah pasien, memudahkan pandangan ke daerah operasi, dan tetap mempertahankan postur yang optimal.

\section{Pemahaman ergonomi ruang Praktek Dokter Gigi untuk Mahasiswa Kedokteran Gigi}

Pentingnya pengenalan akan ergonomi pada meja kerja untuk mahasiswa kedokteran gigi disampaikan pada penelitian yang dilakukan sebelumnya bahwa kebiasaan sistem bekerja dokter gigi dimulai pada saat pelatihan kedokteran sehingga kebiasaan buruk mengenai postur badan saat latihan mengoperasi pasien akan dibawa ketika merawat pasien sebenarnya.

Parameter yang benar untuk ergonomi meja kerja dokter sebagai berikut:

1. Posisi duduk tegap dan simetris

2. Bahu relaks dengan posisi lengan atas berada di samping badan

3. Siku sedikit terangkat

4. Sudut antara paha atas dan paha bawah antara $105-110^{\circ}$

5. Kaki terbuka dengan sudut antara $30-45^{\circ}$

6. Posisi berada di belakang kursi pasien

7. Kepala pasien dapat berotasi dalam 3 arah

8. Lampu sorot dari sebisa mungkin paralel dengan arah pandangan mata

9. Lokasi duduk, membentuk pukul 09.00-12.00 (untuk pengguna kidal 03.00-12.00)nn

10. Kepala pasien dapat dirotasi dan tempat duduknya dapat diatur

11. Instrumen operasi mendapatkan 3 titik support.

\section{Integrated Digital Design dan Engineering}

Rumusan kebutuhan yang telah didapatkan kemudian di visualisasikan dan diproses dengan metode integrated digital design menggunakan software 3DSMAX dengan gambaran seperti dapat dilihat pada Gambar 11.

\section{Prototyping dan riset produksi}

Proses prototyping diawali dengan mempersiapkan dokumen desain dengan ukuran dan dimensi yang telah 
disesuaikan dengan ketersediaan bahan dan komponen peralatan yang harus ada (Gambar 12). Komponenkomponen tersebut antara lain:

1. Sliding manequin mounting

2. Universal dental lamp mounting

3. Table top $24 \mathrm{~mm}$ TACO HPL

4. Emergency button

5. AC cord plug $220 \mathrm{~V}$

6. Stainless steel $30 \times 30 \mathrm{~mm} 1 \mathrm{~mm}$ thickness

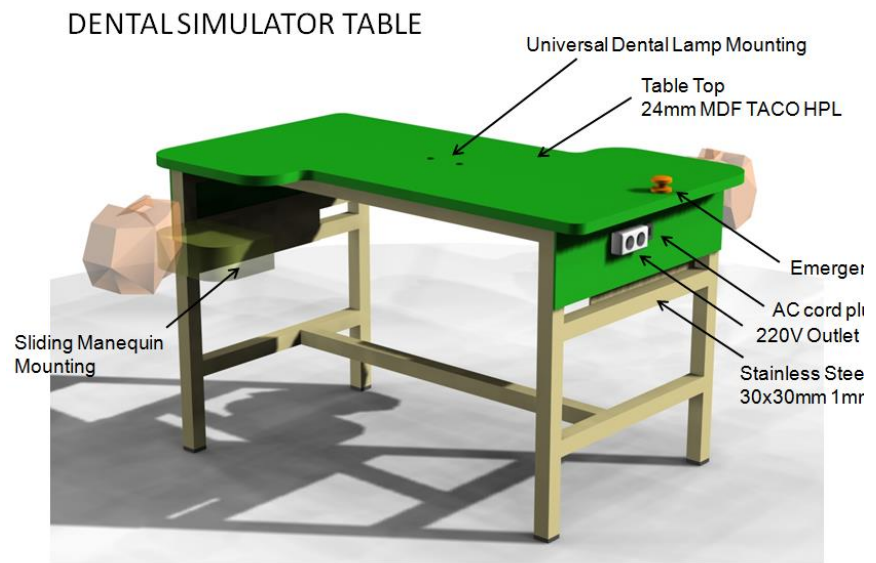

Gambar 12. Rencana spesifikasi dan dimensi produk

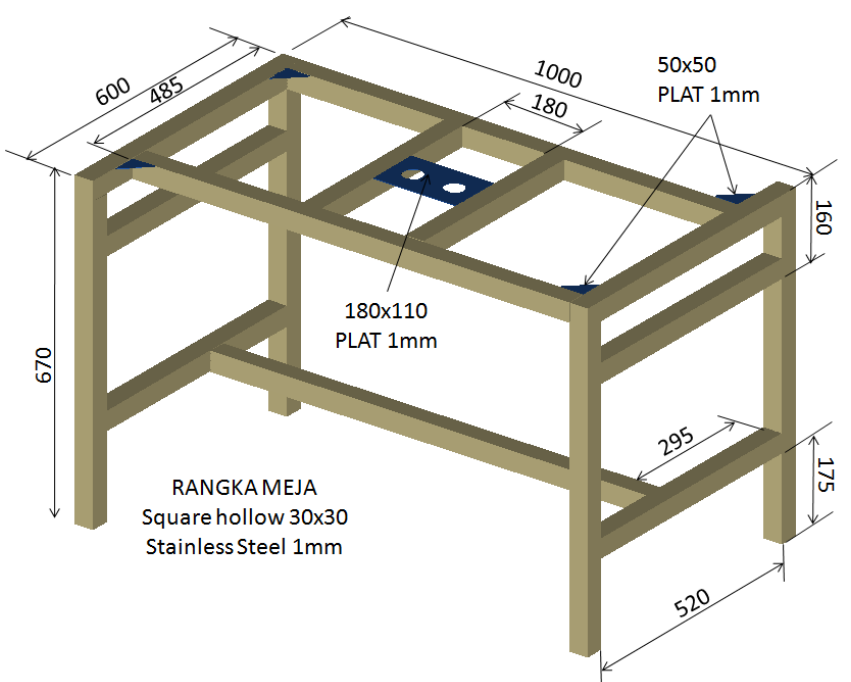

Gambar 13. Dimensi produk rangka meja.
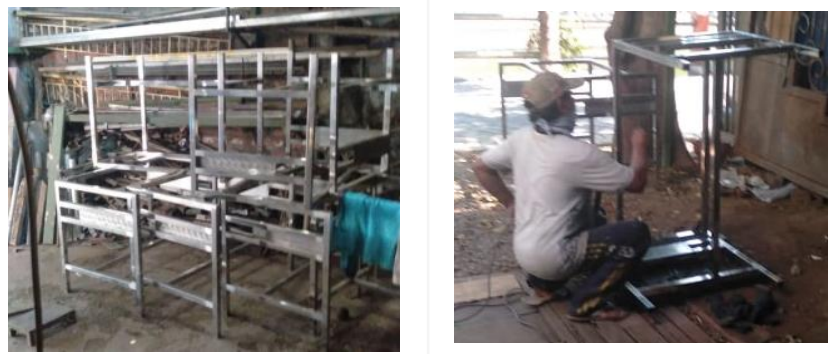

Gambar 14. Proses pembuatan prototipe dan produksi rangka meja

Untuk bagian rangka, material yang digunakan adalah stainless steel dengan detail dimensi seperti pada Gambar 13
Vol. 19, No.2, Oktober 2020, pISSN 1411-3023, eISSN 2580-0264

Desain dengan dimensi dan spesifikasi Gambar 12 dan 13 kemudian dilanjutkan proses pembuatan prototipe dan produksi rangka meja (Gambar 14).

Hasil pembuatan rangka metal kemudian dilanjutkan dengan proses assembling di laboratorium Protomodel Desain Produk ITS untuk melengkapinya dengan top table dan atribut desain lain seperti lampu dan kelistrikan seperti dapat dilihat pada Gambar 15 dan Gambar 16.
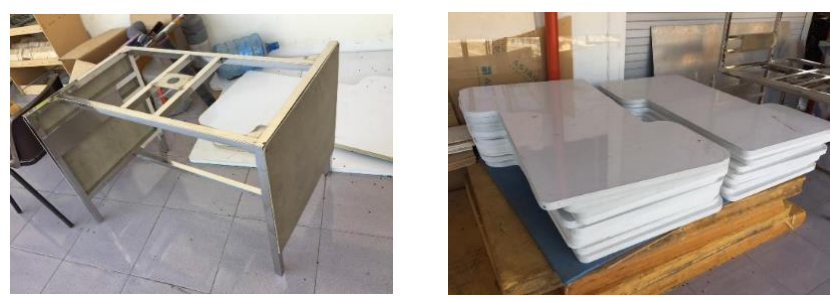

Gambar 15. Rangka metal dan top table.

Sumber: Dokumen laboratorium protomodel Desain Produk ITS
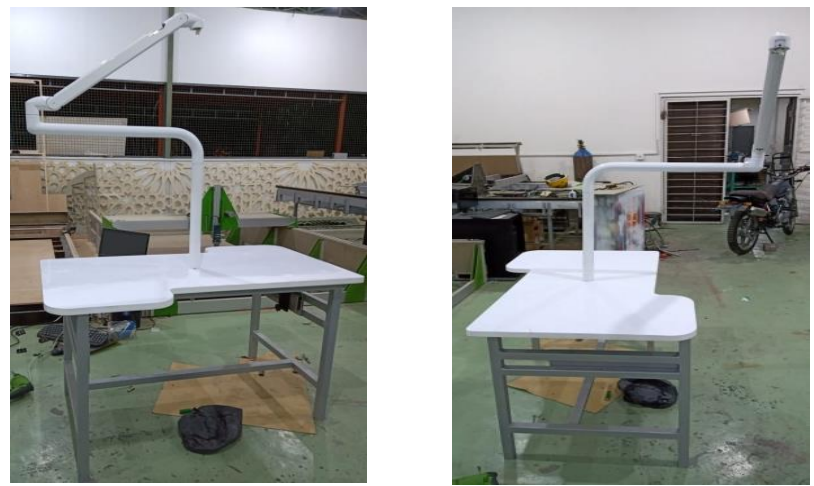

Gambar 16. Pemasangan table top pada rangka metal.

\section{Produksi terbatas}

Produksi terbatas dilaksanakan sebagai awal dari proses finalisasi prototipe 1 (P1) sekaligus digunakan untuk usability test awal (Gambar 17).
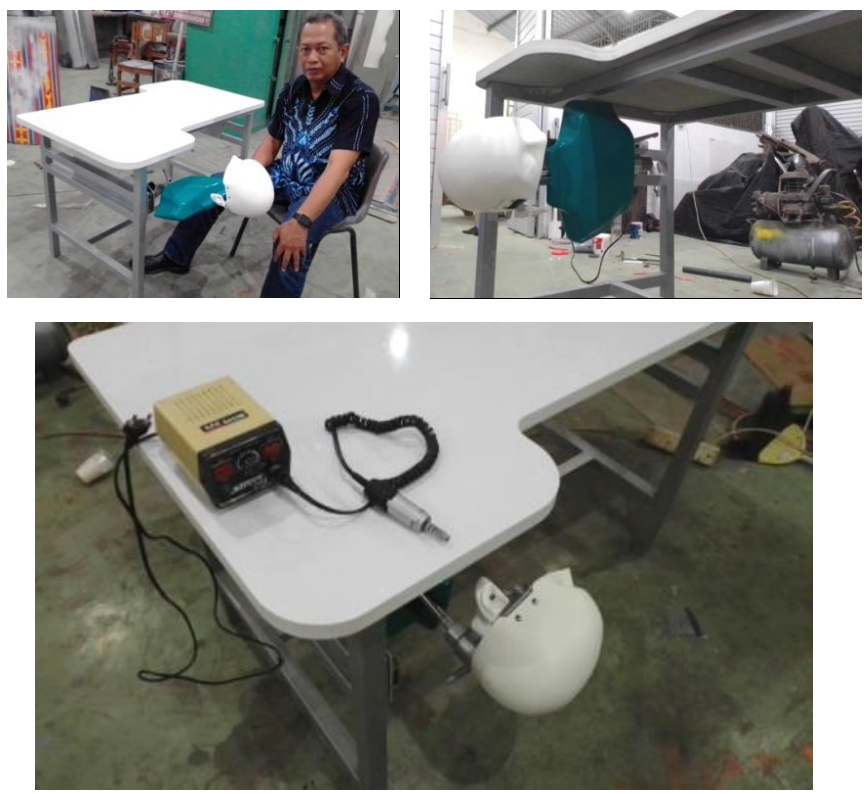

Gambar 17. Prototipe 1. 
Detail Engineering Design dan Development menuju Prototipe 2 (P2)

Hasil dari Prototipe 1 (P1) didapatkan beberapa evaluasi diantaranya :

1. Struktur

2. Efisiensi produksi

3. Komponen yang dapat dikembangkan dan dibuat sendiri

Salah satu yang dapat dikembangkan sebagai prototipe selanjutnya adalah penopang lampu (Gambar 18).
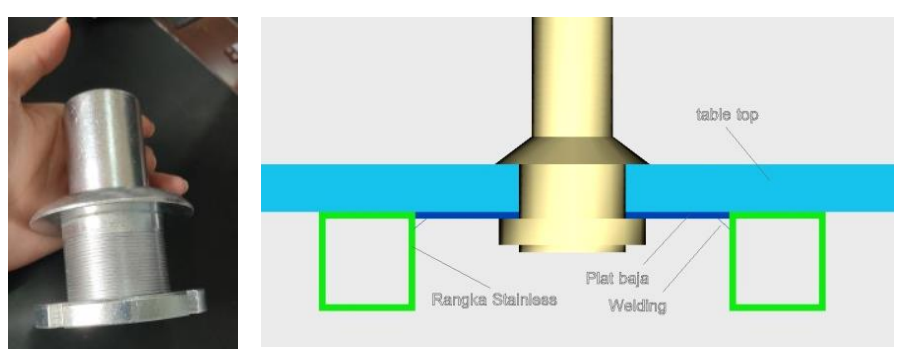

Gambar 18. Pengembangan penopang lampu.

\section{Prototipe Final}

Setelah semuanya ter-assembly, produk kemudian dibawa ke sekolah kedokteran gigi tempat studi kasus untuk dilakukan pengujian/usability test pada area dan user yang sebenarnya yaitu mahasiswa kedokteran gigi (Gambar 19). Pada saat di lapangan, dilakukan terlebih dahulu inspeksi kelayakan oleh dosen pengajar dan praktisi dokter gigi untuk memastikan bahwa fungsi peralatan dan komponen sudah sesuai dengan kebutuhan dan kriteria desain (Gambar 20,21 dan 22).

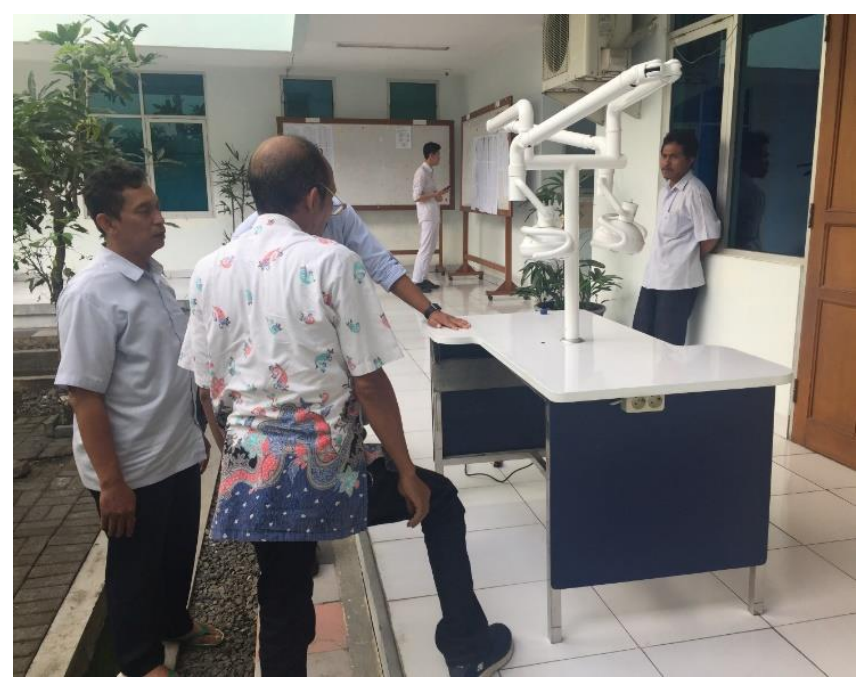

Gambar 19. Pengiriman dan proses uji coba meja dental simulator Kedokteran Gigi di Universitas Hang Tuah.

\section{KESIMPULAN}

Dimensi produk diketahui berdasarkan luasan area, aktivitas kerja praktikan, kenyamanan dan kebutuhan dalam pelaksanaan proses pembelajaran. Pada studi kasus terdapat tambahan tempat kerja pengawas (supervisor) pada konfigurasi penataan unit tempat kerja praktikum dalam satu kelompok. Kelompok tempat kerja diimplementasikan pada ruang kelas/laboratorium dengan pertimbangan jarak untuk jalur sirkulasi.

Komponen peralatan pada workstation sebaiknya memiliki fitur mekanis yang dapat diubah disesuaikan dengan kenyamanan praktikan. Fitur mekanis antara lain sistem putar dummy, naik-turun posisi dan jauh-dekat dengan objek. Kemampuan penyesuaian dalam fitur sebaiknya memperhatikan realitas pada saat menggunakan pasien yang sebenarnya, yang arah ubahan dan posisinya lebih terbatas.

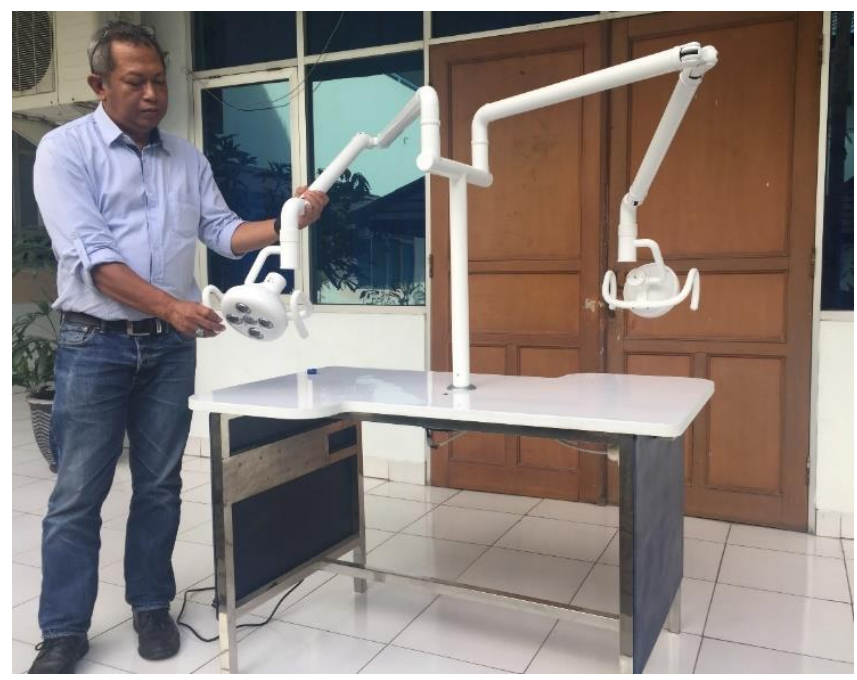

Gambar 20. Inspeksi komponen dan fitur terkait desain Dental Workstation.

Pada saat berpraktik, usaha untuk mendapatkan visual yang baik-jelas pada mulut dan area di dalamnya dan pengendalian penuh atas peralatan praktik yang digunakan menjadi dasar praktikan maupun dokter untuk melakukan gerakan-gerakan dan postur tubuh yang diubah-ubah. Diharapkan produk mampu memfasilitasi ubahan yang diinginkan dan mengurangi sebanyak mungkin beban dan kelelahan yang dialami pada saat bekerja.

Kendala utama dalam proses riset adalah belum maksimalnya proses reverse engineering. Ini dikarenakan tempat dan sekolah studi kasus menggunakan workstation dental simulator hasil modifikasi sebagai eksisting dalam riset ini.

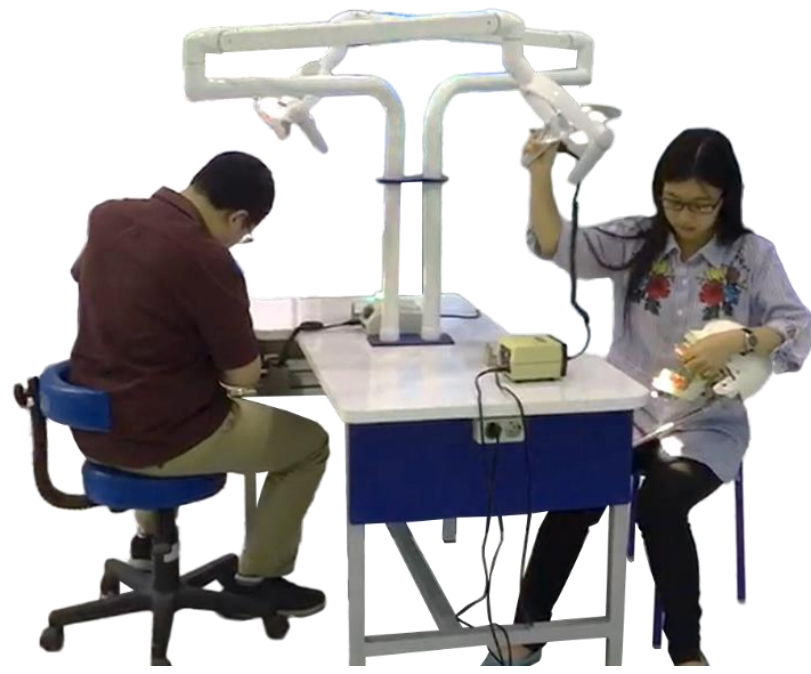

Gambar 21. Uji coba penggunaan desain Dental Workstation. 

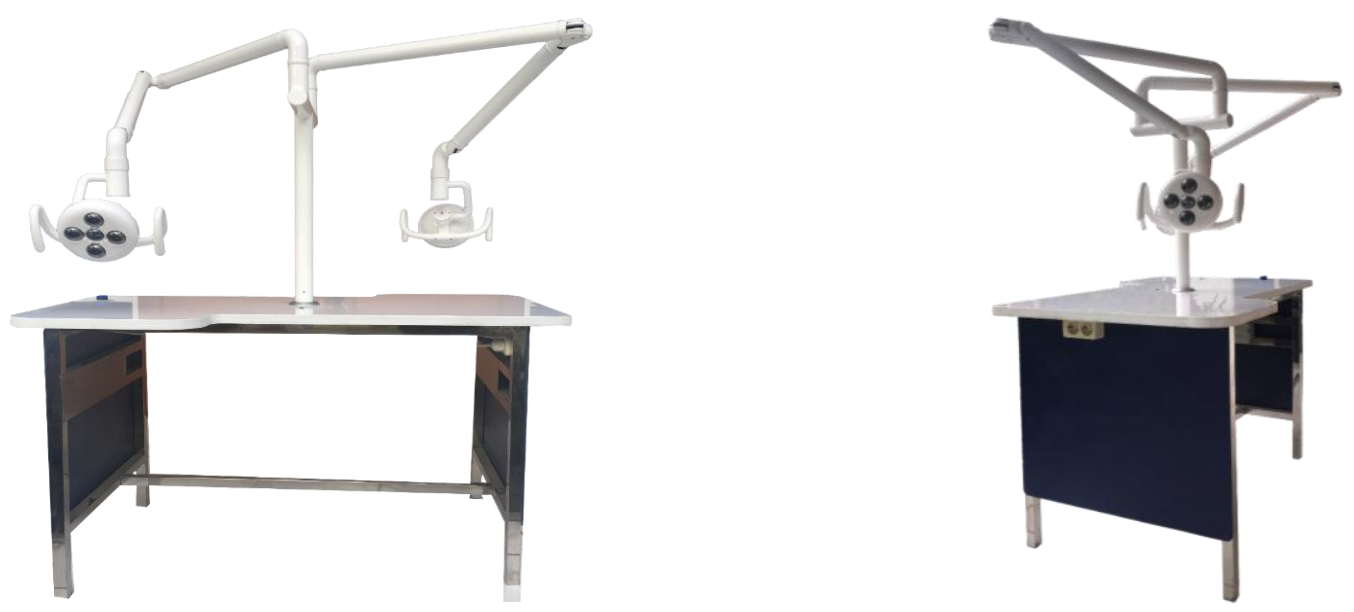

Gambar 22. Prototyping final.

Kendala dalam proses purwarupa adalah proses pemilihan komponen fitting parts dan komponen agar lebih efisien. Beberapa kendala kecil seperti kerapian dapat ditingkatkan pada prototyping selanjutnya. Untuk routing electricity perlu dikembangkan lebih lanjut terkait dengan keamanan (safety) dan perawatan (maintenance).

\section{DAFTAR PUSTAKA}

[1] Fakultas Kedokteran Universitas Brawijaya, Pedoman Akademik Program Studi Pendidikan Dokter, 2013-2014. p.78

[2] Tavkar, A., \& Pawar, A. (2017). Simulation in dentistry. EC Dental Science, 12, 115-121.

[3] Mitchell, D., \& Mitchell, L. (2014). Oxford handbook of clinical dentistry. Oxford University Press, USA. p.381
[4] Sarkar, P. A., \& Shigli, A. L. (2012). Ergonomics in general dental practice. People's J Sci Res, 5(1), 56-60.

[5] Andayasari, L., \& Anorital, A. (2012). Gangguan Muskuloskeletal Pada Praktik Dokter Gigi Dan Upaya Pencegahannya. Media Penelitian dan Pengembangan Kesehatan, 22(2 Jun).

[6] Manji, I. (1992). Designing better dentistry: the ergonomic approach. Journal (Canadian Dental Association), 58(3), 172-173.

[7] Gupta, A., Bhat, M., Mohammed, T., Bansal, N., \& Gupta, G. (2014). Ergonomics in dentistry. International journal of clinical pediatric dentistry, 7(1), 30.

[8] Katrova, L. G. (2012). Ergonomization of the working environment and building up of healthy working posture of dental students. Journal of IMAB-Annual Proceeding Scientific Papers, 18(4), 243-250.

[9] Alsharabasy, A. M. (2018). The Material of Choice for Medical Device Manufacturing

[10] Ashby, M. F., \& Johnson, K. (2013). Materials and design: the art and science of material selection in product design. ButterworthHeinemann. 